\title{
Using KELEA (Kinetic Energy Limiting Electrostatic Attraction) to Improve the Efficiency of Fuel Combustion
}

\author{
W. John Martin \\ Institute of Progressive Medicine, South Pasadena, CA, USA \\ Email:wjohnmartin@ccid.org
}

How to cite this paper: Martin, W.J. (2017) Using KELEA (Kinetic Energy Limiting Electrostatic Attraction) to Improve the Efficiency of Fuel Combustion. Open Journal of Air Pollution, 6, 103-116. https://doi.org/10.4236/ojap.2017.63009

Received: July 28, 2017

Accepted: August 20, 2017

Published: August 23, 2017

Copyright $\odot 2017$ by author and Scientific Research Publishing Inc. This work is licensed under the Creative Commons Attribution-NonCommercial International License (CC BY-NC 4.0).

http://creativecommons.org/licenses/by-nc/4.0/

\section{(c) (i) \& Open Access}

\begin{abstract}
There are many reports of devices and fuel additives being able to enhance the performance of automobiles and other forms of transportation that rely upon the combustion of gasoline or diesel fuels. The claims extend from increased mileage and power to significant reductions in toxic exhaust emissions of carbon monoxide and unburnt hydrocarbons. Progress towards more widespread applications of means of improving fuel efficiency has been impeded by the lack of a coherent explanation of the mechanism of action. Fuel combustion allows for the conversion of much of the available chemical energy in volatile hydrocarbons to mechanical energy, which moves the pistons within an engine. It is proposed that the amount of chemical energy in hydrocarbons can be increased by the absorption of an environmental force termed KELEA (kinetic energy limiting electrostatic attraction). In addition to providing greater mechanical energy with relatively less heat output, the combustion of KELEA activated fuels proceeds further with less toxic emissions of carbon monoxide and unburnt hydrocarbons from incomplete combustion. KELEA activation of fuels should become standard practice in the transportation industry, with potential additional benefits in slowing the rate of global warming.
\end{abstract}

\section{Keywords}

KELEA, Chemistry, Transportation, Hydrocarbons, Combustion, Fuel Efficiency, Air Pollution, Exhaust, Carbon Monoxide, Gasoline, Diesel, Global Warming, Photosynthesis, Hydrogen, Electrical Charges

\section{Introduction}

It is widely assumed that the available chemical energy in organic molecules is originally and entirely derived from energy in sunlight through photosynthesis 
[1]. Plants use sunlight to energetically bind carbon dioxide with water to form carbohydrates, with the release of oxygen [2]. De novo synthesis of organic molecules also occurs in certain bacteria that use sunlight, although oxygen is not necessarily produced [3]. The prevailing, but probably incorrect notion is that without the sun there would be no organic molecules on earth.

The biological reconversion with oxygen of photosynthesized carbohydrates to carbon dioxide and water releases energy that is mainly used to add a third phosphate to adenosine diphosphate (ADP) to generate the high-energy molecule, adenosine triphosphate (ATP) [4]. The ATP can be reconverted to ADP plus phosphate with the release of chemical energy, which is available for the synthesis of other organic molecules. Organic molecules can be structurally changed into specifically different molecules by chemical reactions [5]. These reactions can occur without added energy, providing the total available energy in the reacting molecules exceeds the total available energy in the resulting molecules [6]. Biochemical reactions involving organic molecules typically also require enzymes to concentrate and render minor changes to the reacting molecules [7]. The enzymes act as catalysts to initiate and/or hasten biochemical reactions. Still, unless there is an external source of added energy, the resulting total level of available chemical energy in the reaction products is always less than that of the reactants. The difference in chemical energies between reactants and products is expressed as other forms of energy, including energy required for linked chemical reactions, thermal energy (heat), molecular motion (kinetic energy), sound and/or light (electromagnetic energy).

Water is thought by some to mediate the transfer of energy between different phases of linked chemical reactions [8]. Specifically, it has been suggested that clusters (domains) of water molecules can either be tightly or more loosely bonded and that these forms correlate with low and high energy content, respectively. The energy generating phases of linked chemical reactions presumably leads to the local formations of low density water domains. These domains return to being high density domains upon the transfer of energy to components of the energy dependent phases of linked chemical reactions.

\section{Combustion of Fuels}

The chemical energy in the volatile hydrocarbons, which comprise gasoline and diesel fuels, becomes instantly converted to usable energy upon ignition in internal combustion engines [9]. Ignition is triggered in diesel fuel by pressure and in gasoline fuel by both pressure and electrical spark. During combustion, oxygen from the input of air reacts chemically with the hydrogen and carbon atoms in the injected fuel to yield carbon dioxide gas and water vapor. Using heptane (an alkane hydrocarbon with eight straight-linked carbons) as a representative hydrocarbon, the chemistry of combustion can be expressed in the following formula:

$$
2 \mathrm{C}_{8} \mathrm{H}_{18}+25 \mathrm{O}_{2} \rightarrow 16 \mathrm{CO}_{2}+18 \mathrm{H}_{2} \mathrm{O}+\text { energy }
$$


Incomplete combustion can occur, which results in residual hydrocarbons, free carbon atoms (soot) and/or carbon atoms linked to only a single oxygen atom (carbon monoxide) [9]. Less energy is provided by incomplete than by complete combustion, since there is remaining carbon to hydrogen bonding and because there is more energy retained in free carbon and in carbon monoxide than in carbon dioxide.

\section{Recently Proposed View of Chemical Energy}

The concept of chemical energy is often described as a force holding or bonding different atoms or different molecules in proximity to one another. Individual atoms and molecules are perceived as normally having set amounts of "free energy." A portion of the energy is yielded to the environment as atoms or molecules chemically bond with one another. The amount of energy yielded by the interacting atoms or molecules is directly related to the strength of the bonding. Correspondingly, the yielded energy is inversely related to the energy required for the bonded atoms or molecules to be separated and, thereby, to regain their original "free energy" levels. Traditional chemistry does not provide a clear definition of what constitutes "free energy," as initially proposed by Gibbs [10] [11]. A contradiction exists with the use of terms such as enthalpy and entropy, with one interpretation being that non-attached atoms and molecules have less energy due to entropy, while fixed atoms and molecules have more energy due to enthalpy.

It has been proposed that the chemical energy associated with atoms and molecules is derived from an external force termed KELEA (kinetic energy limiting electrostatic attraction) [12]. This force is hypothesized as being necessary to prevent the fusion and presumed annihilation of electrostatically attracted opposite electrical charges [13] [14] [15] [16] [17]. While initially thought to be only attracted to clearly separated electrical charges, all matter is essentially comprised of electrical charges and can attract KELEA. Thus, atoms are composed of positively charged protons, negatively charged electrons, and ostensibly noncharged neutrons. Yet, both protons and neutrons are composed of electrically charged quarks. Electrically neutral (uncharged) atoms and molecules will commonly become charged by either the loss or gain of electrons prior to a chemical reaction. These changes will add further to the attraction of KELEA to the atoms or molecules. KELEA is, presumably, forever available in the environment allowing for the give-and-take of KELEA by atoms and molecules as they engage in chemical reactions and become again separated, respectively.

In the cited example of heptane combustion, it is now argued that the hydrogen and carbon atoms in heptane are relatively loosely bonded when compared to i) the carbon to oxygen bonds in carbon dioxide; ii) the oxygen to hydrogen bonds in water molecules; and iii) oxygen bonded to itself. KELEA is, therefore, released upon the combustion of heptane and converted into other energy forms, including mechanical energy and intermolecular kinetic friction (heat). 
The level of KELEA in fluids also determines the looseness of intermolecular electrostatic bonding of the molecules [14]. As suggested for water, this reversible looseness can potentially transfer energy between phases of linked chemical reactions [8].

The major implication of this postulate is that KELEA provides an alternative to sunlight as a de novo source of chemical energy. The KELEA derived chemical energy can be incorporated within the molecules and additionally expressed as a looseness of the bonding strength between molecules. KELEA can be a source of energy to drive synthetic reactions in much the same way that sunlight energy can drive photosynthesis. Observations in support of this postulate include 1) the presence of organic molecules at extraterrestrial sites [18] [19]; 2) the greater work output by humans than can be attributed to the chemical energy in the amounts of food consumed [20] and; 3) the formation of complex lipids by alternative cellular energy (ACE) pigments, which attract and transfer KELEA to nearby fluids [12]. Indeed, it has been suggested that the enzyme rubisco, which combines carbon dioxide with water in photosynthesis, may additionally act by capturing and diverting KELEA into carbohydrate synthesis [12].

\section{KELEA Activation of Water}

Many methods have been advocated to increase the health benefits of drinking water. The mechanism of action of some of these methods is commonly assumed to be due to the absorption by water of infrared radiation and/or negative ions [21]. A more updated view, is that the activation results from increasing the level of KELEA in the water [13] [14] [15] [16] [17]. This can be achieved by either adding KELEA attracting materials to the water or by placing the water in an environment with heightened levels of KELEA. Among the KELEA attracting materials are various dipolar compounds, some of which are commonly used by farmers intending to restore minerals into the soils. These include humic/fulvic acids, zeolites, volcanic rocks, mica, shungite, magnesium oxide and other metal oxides. Many of these compounds are available as pellets, such as Kiko pellets, which comprise volcanic rock materials, which is ground and heated prior to pelleting. Soluble extracts and tinctures of various plants and herbs can be added in small quantities to water. An example is the hot water extract of the sap from several Japanese trees and plantain, called HB-101. Several gases including hydrogen and Brown's gas, which is an electrolysis generated mixture of hydrogen, oxygen and non-thermal vaporized water molecules [22], can also be bubbled into water as a means of KELEA activation. Electrolysis of water can also occur if there is contact within the water between metals with differing electronegativity (triboelectrification). This spontaneous electrolysis can also occur with different metals incorporated into various alloys. Once water is sufficiently activated, it can be used to activate additional water during progressive dilutions, as is practiced in homeopathy [23].

Locally elevated levels of KELEA can be achieved by using various electrical and magnetic devices with rapid on-off switching. Opposing electrical currents 
and converging light paths can also be used [24] [25]. Regular water can also be slowly activated by simply being placed in proximity to some of the other materials that can directly activate water by being added to the water. One example is the wide range of mineral oxides incorporated into Miron glass bottles

(http://www.miron-glas.com/). These bottles provide a useful container in which to activate water. Another approach involves the use of a sealed inner container of previously activated water, within a larger container of flowing water. This type of water activating device was pioneered by Johann Grander, who used water from an Austrian mine. The water was naturally activated, probably because of the presence of copper-containing materials.

As noted above, the major physical difference between activated and regular water is a loosening of the hydrogen bonding between the water molecules [14]. This leads to lower surface tension, slight expansion in volume, greater volatility and other changes. As also noted above, ACE pigments in the appropriate medium can lead to the biosynthesis of lipids (hydrocarbons), presumably by attracting KELEA into water in the presence of carbon and hydrogen atoms [15] $[20]$.

\section{Increasing KELEA Levels in Gasoline and Diesel Fuels}

Several of the currently available water activating methods, along with other approaches, have been coincidentally applied to improving the performance of gasoline and diesel fuels. It is now reasonable to interpret these improvements as resulting from the input of KELEA into the fuels. Actual field testing has confirmed significant benefits of KELEA activated fuels in terms of increased mileage and by other criteria. Particularly informative methods of fuel activation by KELEA will be briefly described.

The first indication to the author of a possible overlap between the activation of water and that of gasoline was provided by Mr. Nobo Azuma, representing a Japanese company called YK Flora Ltd. He was marketing an extract from Japanese trees and plantain termed HB-101. When it is added to agricultural water at 1:10,000 dilution, it increases the yield of various crops and extends the shelf life of the harvested crops. HB-101 is also beneficial as an additive to animal feed, leading to faster growth and greater egg production by chickens, increased milk production by cows, etc. Mr. Azuma would regularly travel to meet with farmers in rural California. Before embarking upon such trips, he would add $100 \mathrm{ml}$ of HB-101 to the 70-liter fuel tank of his 2001 Toyota Camry. This would reliably provide an estimated $25 \%$ greater distance that he could travel between refueling.

A different approach to improving gas mileage was demonstrated to me by Tom and Bill Lang (http://www.watertogas.com/). They and others had followed the report of Archie Blue that cars could be driven by combusting the hydrogen and oxygen gases generated by water electrolysis. This finding evolved into a system of supplementing gasoline combustion using electrolysis generated gases 
introduced into the air inflow of automobiles. The electrolysis generated gases are referred to as Brown's gas after Yul Brown, or as HHO [22]. The HHO designation is derived from an understanding that vaporized water is an additional component to the hydrogen and oxygen gases generated by the electrolysis of water. The Lang brothers manufactured and sold their Brown's gas generating device to numerous automobile and truck owners. In addition to improved gasoline and diesel mileage, reliably estimated to be more than $10 \%$, customers regularly reported improved power, such that cars and trucks could remain in a higher gear when driving up hills, or would show less strain when towing a heavy load. Many devices listed as either providing Brown's gas or HHO are currently being marketed on the Internet for both automobiles and trucks. Published studies have confirmed improved mileage and power with more complete combustion using this approach [26] [27] [28].

Specially prepared volcanic rock materials provide yet another approach to improved fuel economy. As previously reported, the addition of six Kiko pellets to the gasoline tank, or pretreating 1 - 4 liters of gasoline for several hours with Kiko pellets, before adding it to gasoline already in a gas tank, achieved from 10 to $43 \%$ improved fuel economy in different cars [29]. In two separate determinations at different locations, Kiko pellets significantly reduced the measurable exhaust levels of both carbon monoxide and unburnt hydrocarbons. The reductions were $60.0 \%$ and $89.7 \%$ for carbon monoxide and $53.3 \%$ and $60.0 \%$ for unburnt hydrocarbons, respectively.

Two cartridges, each containing approximately 50 Kiko pellets, were placed into a 10,000 gallon above ground diesel storage unit. A John Deere Model 7760 cotton harvester would fill up from the tank daily and run at a constant speed throughout an 8-hour day. Prior to adding the Kiko cartridges, the harvester required 378 gallons per 8-hour day. With Kiko activated fuel, the harvester needed only 288 gallons of diesel a day; a $24 \%$ fuel saving. A water pivot used for irrigating the cotton fields required $10 \%$ less fuel when using activated diesel to maintain the daily operations [29].

A commercially available method for achieving fuel activation is provided by attaching a 6-inch container of activated fluid to the outside of the vehicle's fuel line. This system, previously called Gas Mojo and more recently CFTplus, has been installed on several hundred automobiles, numerous trucks and farm equipment. Instillation is stated to achieve a minimum improved mileage of approximately $15 \%$. Particularly notable is the reduced idling speed of the engines (typically around 25\%, e.g. from 1000 to $750 \mathrm{rpm}$ ) and the slower speeds at which the transmission shifts from a lower to a higher gear (by about $5 \mathrm{mph}$ ) [29]. Both factors undoubtedly contribute to the increased gas mileage, especially in cities where up to $30 \%$ of fuel consumption occurs when engines are idling and higher gears are more fuel efficient than lower gears. Treated vehicles can display an increase in power. For example, a diesel truck required 11.7 seconds to accelerate $0-60 \mathrm{mph}$. After installing the Gas Mojo device, the same truck required only 7.4 seconds to reach $60 \mathrm{mph}$ (duplicate readings). A marked re- 
duction in both the smoky appearance and the smell of diesel exhaust is consistently observed in trucks with the installed device [29]. This is also seen as less soot deposited in the exhaust pipe. The major significance of this approach to fuel activation is that there is no requirement for direct contact between the fuel and the activating device. Accordingly, the device is exempt from Federal registration under 40 CFR Part 79.

Another commercially available system to improve fuel efficiency was introduced in the early 1990's. It is called the Fitch's catalyst and details are provided in various US patents [30] [31] [32]. It was originally comprised of a 4-metal alloy, predominantly comprising antimony and tin, with additional lead and mercury. Some of the tin was said to be oxidized [33]. Various additional metals have since been incorporated into the alloys. These include zinc, silver, magnesium, cerium, copper, palladium and aluminum. The combinations of metals are chosen to include metals with differing electronegativity, such that some can potentially function as the anode and others as the cathode in electrolysis. Indeed, hydrogen gas is generated when the device is placed into ethanol. The alloys are provided either as a canister, which is installed into the fuel line, or as metal "drop-in" pieces added to the fuel tank (https://fitchfuelcatalyst.com/). In addition to the benefits of increased mileage, Fitch treated fuels deteriorate less over time when compared to untreated fuels (marketed as a fuel stabilizer).

A major claim for the Fitch device is that it catalyzes the formation of new combustible hydrocarbons, possibly by means of hydrogen gas generated from the metal alloys [32]. Specifically, gas chromatography-mass spectroscopy (GCMS) studies on treated gasoline and diesel showed highly significant increases in the levels of combustible aromatic and other energy-rich hydrocarbons. The manufacturer assumed that the newly formed combustible hydrocarbons were derived from the cleavage of higher molecular weight, non-combustible hydrocarbons. This assumption was predicated on the understanding that, without energy input, preexisting, low molecular weight hydrocarbons could not be transformed into higher energy hydrocarbons. Inspection of the provided GC-MS data shows that this type of transformation might be occurring since the relative levels of lower molecular weight hydrocarbons between untreated and treated fuels are reduced. Moreover, the alterations in the relative amounts of different hydrocarbons occur with Indolene, a highly-refined gasoline with very minimal non-combustible material. Tin based alloys have been developed by several other companies as fuel catalysts, e.g. Broquet International (https://www.broquet.com/; https://www.carbonflo.com). The manufacturers of these devices generally appear to assume that the primary mode of action is the production of hydrogen gas.

Other devices employ different minerals, such as anodized aluminum (fuelcat.co.uk) or contain minerals mixed with various dipolar materials, such as zeolites (http://www.getrentar.com/). It is noteworthy that the zeolite/mineral complexes in the Rentar fuel line cartridges are embedded into a fuel resistant resin [34]. There is, therefore, no direct contact of the zeolite/mineral complexes with 
the flowing fuel. A similar non-contact feature exists with various combinations of ceramics (primarily mineral oxides) and pyroelectric materials, such as tourmaline [35] [36]. These manufacturers attribute the improved fuel performance primarily to the emission of infrared radiation and possibly also to negative ions. On the belief that the energizing capacity of the minerals is mediated by infrared radiation, customers are advised to place cartridges containing the minerals on non-metal sections of the fuel line. Data substantiating the lack of activity through metal sections of the fuel line are not provided.

Some of the metal devices include magnetic material on the assumption that the magnets can reorient dipolar hydrocarbons flowing through the fuel line. Other proponents simply use magnets, with preference shown for having magnets with identical facing poles tied onto the fuel line. This creates a magnetic repulsive force within the fuel line. A magnet is empirically also used on the anode of certain Brown's gas generating devices installed into automobiles (unpublished).

Several fluid formulations are being marketed to increase fuel economy and to prevent the age deterioration of fuels [37]. There is extensive documentation that the combustion of fuels treated with these various formulations is more complete than that of untreated fuels, with significantly $(>50 \%)$ reduced levels of carbon, unburnt hydrocarbons and carbon monoxide exhaust. These emission reductions are especially notable in the combustion of crude diesel (bunker fuel) in cargo ships. The reported improved mileages for land vehicles are also impressive. Examples of these products include PRI-D and PRI-G, (for diesel and gasoline fuels, respectively), manufactured by Power Research Institute (http://priproducts.com/) and FPC manufactured by Fuel Performance Catalyst (http://www.fpc1.com/). The PRI products comprise Shellsol D60 (a 50:50 paraffin and naphthalene mixture with $10-12$ carbons), together with a proprietary mixture of amines and dispersants. The FPC product contains ferrous picrate, for which a patent for improved combustion and reduced carbon exhaust emission was awarded in 1944 [38].

Of special note is the PRI and FPC manufacturers' claims, along with supportive customer reports, that in addition to preventing fuels from becoming stale, there is a reversal of the process of natural oxidation using their respective products. Thus, as with the Fitch catalyst, the PRI and FPC products restore stale fuel to a more energized state. Several additional fuel additives are reported to do the same. The PRI and FPC fuel additives, as well as the Gas Mojo device, have an additional capacity to increase the miscibility of any separated water within the stale fuels. Hydrocarbon metabolizing bacteria can more readily grow in larger water droplets and this can adversely affect the quality of the fuel. Less bacteria growth occurs in diesel treated with the Fitch device [33].

Table 1 summarizes the commonly reported improvements in the performance of treated fuels. The improvements have been noted in automobiles, trucks, farm and industrial equipment, shipping and railways. Although not 
Table 1. Improvements in fuel combustion.

1) Increased mileage per gallon of fuel consumed (typically $~ 15 \%$ with refined fuels)

2) Increased power, variously expressed as lower idle speed, earlier transition from lower to higher gears, faster acceleration, greater pulling power, etc.

3) Reduced emissions of carbon particulates (soot), unburnt hydrocarbons and carbon monoxide

4) Reversal of previously accumulated carbon deposits within engine and tail pipe, allowing for further improvements in engine performance over time

5) Reduced separation of water from fuel with less growth of hydrocarbon-metabolizing, contaminating bacteria

6) Less deterioration of fuel during long-term storage

discussed in this paper, the efficiency of fuel used in heating can also be improved by similar procedures. So too can water become more easily heated, for example in the production of steam, if the water is pretreated by each of the described procedures. Table 2 summarizes some of the varying suggested mechanisms and methods of improving the performance of fuels. As included in this Table, a unifying view of fuel activation is the absorption of KELEA. The next section discussed the various mechanisms by which KELEA can enhance fuel efficiency.

\section{Mechanisms Leading to Improved Performance of KELEA Activated Fuels}

The marked increase in energy output upon combustion of KELEA activated gasoline and diesel fuels is attributable to several factors. A minor factor in the improved fuel economy (miles per gallon) is the more complete combustion of the fuel, as shown by the lower exhaust emission levels of carbon monoxide and unburnt hydrocarbons. Gasoline vehicles are equipped with catalytic converters [39], which oxidize a portion of the gases coming from the engine to the exhaust pipe. Despite having a catalytic converter, there is still considerable lowering in the level of toxic exhaust gases from vehicles using KELEA activated gasoline [29]. A more reliable indication of improved combustion is seen in vehicles using KELEA activated diesel fuel. These vehicles do not have catalytic converters. The reduction in unburnt hydrocarbons is not only easily measurable, but is very apparent from the markedly improved smell of the vehicles' exhaust. The exhaust levels of unburnt hydrocarbon and carbon monoxide with untreated diesel indicate that far less than $10 \%$ of the fuel is incompletely oxidized. The observed partial lowering of these exhaust levels with treated diesel is, therefore, unable to explain the approximate $15 \%$ achievable improved mileage.

A second factor that contributes to increased fuel efficiency by various additives is that more of the fuel energy is apparently converted to mechanical work rather than being diverted to heat. It is likely that the added preexisting kinetic energy and increased vaporization of KELEA activated fuels contribute to faster burning. This is relevant since the speed of combustion plays a role in the relative 
Table 2. Proposed mechanisms and methods for improving fuel efficiency.

\begin{tabular}{|c|c|}
\hline $\begin{array}{c}\text { Infrared radiation } \\
\text { (With or without negative ions) }\end{array}$ & $\begin{array}{c}\text { Volcanic rock (ground and heated), } \\
\text { zeolites, other ceramics, minerals }\end{array}$ \\
\hline $\begin{array}{l}\quad \text { Hydrogen gas production } \\
\text { (With or without non-thermal water vapor) }\end{array}$ & $\begin{array}{l}\text { Brown's gas, triboelectric charged } \\
\text { metal alloys }\end{array}$ \\
\hline $\begin{array}{l}\text { Reformulation of fuel with increased } \\
\text { combustible hydrocarbons and/or } \\
\text { reduced natural oxidation of the fuel }\end{array}$ & $\begin{array}{l}\text { Metal alloys, ferrous picrate, various } \\
\text { hydrocarbon formulations }\end{array}$ \\
\hline Reorientation of the fuel molecules & Magnets \\
\hline $\begin{array}{l}\text { KELEA (kinetic energy limiting } \\
\text { electrostatic attraction) }\end{array}$ & $\begin{array}{l}\text { All the above, fuel in proximity to } \\
\text { KELEA activated fluids, other } \\
\text { activating materials and/or devices }\end{array}$ \\
\hline
\end{tabular}

amounts of outward pressure exerted by the expanding gases. Thus, the faster burning of fuels can yield a higher ratio of increased pressure to heat within internal combustion engines. This results in greater mechanical energy expressed as increased power and rate of acceleration and allows for lower idling speeds before the engine stalls. It is also noted that engines running at a lower temperature can greatly diminish the oxidation of nitrogen, which leads to the production of nitrogen oxides as additional toxic exhaust gases.

The third and presumably the major reason for the increased efficiency of KELEA activated fuels is the proposed additional chemical energy incorporated into the hydrocarbon molecules. This would increase the overall energy yield upon the conversion of the hydrocarbons plus oxygen to carbon dioxide and water vapor. Even more intriguing is the apparent capacity of the additional chemical energy to transform short chain hydrocarbons into longer chain length molecules and to energy-rich aromatic compounds, as suggested with the Fitch device. While the device could possibly be working solely through the production of hydrogen [32], the reforming of higher energy hydrocarbons is more consistent with the input of KELEA into the fuel. The proposed capacity of KELEA to synthesize hydrocarbons can also explain the apparent rejuvenation of stale fuels reported with several fuel additives. Added chemical energy available from KELEA is, therefore, proposed to be the most significant factor in increasing fuel economy.

In much the same way that various fuel additives can reverse the normal oxidation of fuels, it is reported that switching to activated fuels can lead to the removal of preexisting carbon and hydrocarbon deposits. This can be explained by enhanced molecular separation of aggregated carbon particles induced by KELEA. Some of the marketed products, including the Fitch and Gas Mojo devices, also describe increased miscibility of any formed water (a feature of low sulfur diesel fuels and of ethanol containing gasolines). As noted above, the reduction in separated water reduces bacterial contamination, which can especially occur with diesel fuels [33]. 
It would seem beneficial for refineries to use fuel economy-enhancing fuel additives at the production sites. One concern is the increased volatility and flammability of activated fuels. This could potentially add to evaporation losses during shipping and to the risk of explosions. These issues are of less concern to the end user. Studies should be conducted to compare the relative efficiencies of the various available approaches to the KELEA activation of fuels. Each method can be further adjusted based on the capacity to contribute optimal chemical energy to the respective fuels. Placing a container of activated water near the vehicle's fuel tank or to a fuel storage tank provides a relatively simple approach to achieving greater fuel economy and reducing atmospheric levels of carbon monoxide and unburnt hydrocarbons. The amounts of fuels used in transportation were estimated to be over 46 million barrels a day in 2014. Achieving a 10\% reduction in fuel consumption is not insignificant financially. When the additional benefit of reduced emissions of toxic hydrocarbons and carbon monoxide are considered, it should be standard practice to be using KELEA activated fuels in the transportation industry. There are related benefits for using KELEA activated fuels in furnaces and KELEA activated water in providing the steam to drive turbines.

\section{Conclusion}

This review offers a potential explanation for the improved performance of diesel and gasoline fuels seen with various devices and fuel additives. Manufacturers report improvements in mileage and power output, which are consistent with the postulated input of an environmental force termed KELEA (kinetic energy limiting electrostatic attraction). It is proposed that KELEA adds to the chemical and kinetic energy of the hydrocarbon molecules in fuel. Consequently, more energy can be released upon the combustion of KELEA activated fuels, when compared to non-activated, regular fuels. Moreover, the combustion proceeds further with reduced levels of emission of unburnt hydrocarbons and carbon monoxide. The methods for activating fuels are comparable to those used to increase the level of KELEA in water. Essentially, activation can be achieved by either adding KELEA attracting and releasing dipolar compounds to the fuels or by creating a heightened KELEA energy field close to the fuel. Hydrogen gas and Brown's gas are regarded as being dipolar additives, although they are also directly combustible. It is speculatively proposed that KELEA functions as the basic energy of chemicals, being equivalent to what is normally regarded as chemical energy. This is relevant to basic biology since sunlight via photosynthesis was previously considered as the only de novo source of energy for the formation of organic molecules. KELEA can potentially supply energy for hydrocarbon molecules to undergo chemical transformations, as suggested by chromatogram results using the Fitch Catalyst. KELEA may also reverse the natural oxidation resulting in stale fuels. More targeted experiments need to be conducted to better define KELEA as an energy source. 


\section{Acknowledgements}

Information about the performance of various devices and fuel additives was received from several individuals. Longer discussions were held with the developer of the Kiko Technology, Gas Mojo device and a Brown's gas generating fuel system. The Institute of Progressive Medicine is a component of MI Hope Inc., a non-profit public charity.

\section{Conflict of Interest}

None.

\section{References}

[1] Raghavendra, A.S. (1998) Photosynthesis. A Comprehensive Treatise. Cambridge University Press, Cambridge, 377.

[2] Pessarakli, M. (2016) Handbook of Photosynthesis. 3rd Edition, CRC Press, Boca Raton, FL, 846. https://doi.org/10.1201/b19498

[3] Saer, R.G. and Blankenship, R.E. (2017) Light Harvesting in Phototrophic Bacteria: Structure and Function. The Biochemical Journal, 474, 2107-2131. https://doi.org/10.1042/BCJ20160753

[4] Prebble, J.N. (2010) The Discovery of Oxidative Phosphorylation: A Conceptual Off-Shoot from the Study of Glycolysis. Studies in History and Philosophy of Biological and Biomedical Sciences, 41, 253-262. https://doi.org/10.1016/j.shpsc.2010.07.014

[5] Nelson, D.L. and Cox, M.M. (2017) Lehninger Principles of Biochemistry. 7th Edition, W.H. Freeman, New York, 1328.

[6] Toure, O. and Dussap, C.-G. (2016) Determination of Gibbs Energies of Formation in Aqueous Solution Using Chemical Engineering Tools. Bioresource Technology, 213, 359-368. https://doi.org/10.1016/j.biortech.2016.02.109

[7] Robinson, P.K. (2015) Enzymes: Principles and Biotechnological Applications. Essays in Biochemistry, 59, 1-41. https://doi.org/10.1042/bse0590001

[8] Wiggins, P. (2008) Life Depends upon Two Types of Water. PLoS ONE, 3, e1406. https://doi.org/10.1371/journal.pone.0001406

[9] Erjavec, J. and Thompson, R. (2014) Automotive Technology: A Systems Approach. 6th Edition, Delmar, Clifton Park, NY, 1696.

[10] Gibbs, J.W. (1875) On the Equilibrium of Heterogeneous Substances. Transactions Connecticut Academy, 3, 108-524.

[11] Malone, L.J., Dolter, T.O. and Gentemann, S. (2013) Basic Concepts of Chemistry. 9th Edition, John Wiley \& Sons, Hoboken, 588.

[12] Martin, W.J. (2017) Is KELEA (Kinetic Energy Limiting Electrostatic Attraction) a Source of Chemical Energy? MOJ Bioorganic \& Organic Chemistry, 1, Article No. 00011 .

[13] Martin, W.J. (2014) Stealth Adapted Viruses; Alternative Cellular Energy (ACE) \& KELEA Activated Water. Author House, Bloomington, 321.

[14] Martin, W.J. (2015) KELEA: A Natural Energy That Seemingly Reduces Intermolecular Hydrogen Bonding in Water and Other Liquids. Open Journal of Biophysics, 5, 69-79. https://doi.org/10.4236/ojbiphy.2015.53006

[15] Martin, W.J. (2015) KELEA Activation of Water and Other Fluids for Health, 
Agriculture and Industry. Journal of Water Resource and Protection, 7, 1331-1344. https://doi.org/10.4236/jwarp.2015.716108

[16] Martin, W.J. (2015) Improved Efficiency of Heat Exchange Using KELEA Activated Water. Open Journal of Energy Efficiency, 4, 36-43. https://doi.org/10.4236/ojee.2015.42004

[17] Martin, W.J. (2016) KELEA (Kinetic Energy Limiting Electrostatic Attraction) Offers an Alternative Explanation to Existing Concepts Regarding Wave-Particle Duality, Cold Fusion and Superconductivity. Journal of Modern Physics, 7, 1995-2007. https://doi.org/10.4236/jmp.2016.715176

[18] Pizzarello, S., Cooper, G. and Flynn, G. (2006) The Nature and Distribution of the Organic Material in Carbonaceous Chondrites and Interplanetary Dust Particles. In: Meteorites and the Early Solar System II, Univ. Arizona Press, 625-651.

[19] De Sanctis, M.C., Ammannito, E., McSween, H.Y., Raponi, A., Marchi, S., Capaccioni, F., et al. (2017) Localized Aliphatic Organic Material on the Surface of Ceres. Science, 355, 719-722. https://doi.org/10.1126/science.aaj2305

[20] Martin, W.J. (2016) Insufficiency of Cellular Energy (ICE) in Neurons, from Electrical Hyperactivity to Quiescence. International Journal Complementary Alternative Medicine, 4, Article No. 00118.

[21] Pangman, M.J. and Evans, M. (2017) Dancing with Water; The New Science of Water. 2nd Edition, Word Press, 275.

[22] Hurtak, J.J. and Hurtak, D. (2014) The History and Future of Brown's Gas. Nexus Magazine, 21, 45-54.

[23] Bornhoft, G. and Matthiessen, P.F. (2011) Homeopathy in Healthcare-Effectiveness, Appropriateness, Safety, Costs. Springer Publishing, New York, 209.

[24] Martin, W.J. (2015) Interactive Electric Fields Can Attract KELEA (Kinetic Energy Limiting Electrostatic Attraction) and Can Lead to the Activation of water. International Journal Complementary \& Alternative Medicine, 1, Article No. 00034. https://doi.org/10.15406/ijcam.2015.01.00034

[25] Martin, W.J. (2015) Interacting Light Paths Attract KELEA (Kinetic Energy Limiting Electrostatic Attraction) and Can Lead to the Activation of Water. Open Journal of Biophysics, 5, 115-121. https://doi.org/10.4236/ojbiphy.2015.54010

[26] Yilmaz, A.C., Uludamar, E. and Aydin, K. (2010) Effect of Hydroxy (HHO) Gas Addition on Performance and Exhaust Emissions in Compression Ignition Engines. International Journal Hydrogen Energy, 35, 11366-11372.

[27] Musmar, S.A. and Al-Rousan, A.A. (2011) Effect of HHO Gas on Combustion Emissions in Gasoline Engines. Fuel, 90, 3066-3070.

[28] El-Kassaby, M.M., Eldrainy, Y.A., Khidr, M.E. and Khidr, K.I. (2016) Effect of Hydroxy (HHO) Gas Addition on Gasoline Engine Performance and Emissions. Alexandria Engineering Journal, 55, 243-251.

[29] Martin, W.J. (2016) KELEA (Kinetic Energy Limiting Electrostatic Attraction) Can Markedly Improve the Performance of Gasoline and Diesel Fuels in Power Generation and in Transportation. Journal of Transportation Technologies, 6, 148-154. https://doi.org/10.4236/jtts.2016.63014

[30] Wright, R.H. (1998) Fuel Treatment Device. US Patent No. 5738692. United States Patent and Trademark Office, Alexandria.

[31] Berlin, A.J. and Wright, R.H. (2012) Apparatus and Method for Resuscitating and Revitalizing Hydrocarbon fuels. US Patent No. 8298405. United States Patent and Trademark Office, Alexandria. 
[32] Berlin, A.J. and Wright, R.H. (2014) Method and Device for Treating Fuel. US Patent No. 6770105. United States Patent and Trademark Office, Alexandria.

[33] Ghosh, R., Koerting, C., Suib, S.L., Best, M.H. and Wright, A.J. (2005) Effect of a Metal Alloy Fuel Catalyst on Bacterial Growth. Langmuir, 21, 10655-10661. https://doi.org/10.1021/la050912k

[34] Ratner, J. (2016) Fuel Conditioning Modules and Methods.US Patent No. 9364809. United States Patent and Trademark Office, Alexandria.

[35] Wey, A.C.-T. (2015) Infrared Assisted Hydrogen Generation. US Patent No. 9180424. United States Patent and Trademark Office, Alexandria.

[36] Wey, A.C.-T. (2016) Infrared-Emitting Ceramics for Fuel Activation.US Patent No. 9388735. United States Patent and Trademark office, Alexandria.

[37] Srivastava, S.P. and Hancsok, J. (2014) Fuels and Fuel-Additives. John Wiley \& Sons Inc., Hoboken, 376. https://doi.org/10.1002/9781118796214

[38] Boardman, H. (1944) Fuel for Internal-Combustion Spark Ignition Engines. US Patent Publication Number US2506539 A. United States Patent and Trademark Office, Alexandria.

[39] Taylor, K.C. (2012) Automobile Catalytic Converters. Springer-Verlag, Berlin, 56.

\section{Abbreviations}

KELEA: kinetic energy limiting electrostatic attraction, ACE: alternative cellular energy, ADP: adenosine diphosphate, ATP: adenosine triphosphate, GC-MS: Gas Chromatograph-Mass Spectroscopy, mph: miles per hour.

\section{Submit or recommend next manuscript to SCIRP and we will provide best} service for you:

Accepting pre-submission inquiries through Email, Facebook, LinkedIn, Twitter, etc. A wide selection of journals (inclusive of 9 subjects, more than 200 journals)

Providing 24-hour high-quality service

User-friendly online submission system

Fair and swift peer-review system

Efficient typesetting and proofreading procedure

Display of the result of downloads and visits, as well as the number of cited articles

Maximum dissemination of your research work

Submit your manuscript at: http://papersubmission.scirp.org/

Or contact ojap@scirp.org 